\title{
SOSIALISASI BUDIDAYA BUAH NAGA UNTUK DAERAH PESISIR DI DESA CINTARATU, PARIGI, KABUPATEN PANGANDARAN
}

\author{
Sudarjat \\ Universitas Padjadjaran
}

Vijaya Isnaniawardhani
Universitas Padjadjaran

Muhamad Abdilah Hasan Qanit

Universitas Padjadjaran

Syariful Mubarok *

Universitas Padjadjaran

\begin{abstract}
SOCIALIZATION OF DRAGON FRUIT CULTURE FOR COASTAL REGION IN CINTARATU VILLAGE, PARIGI, DISTRICT OF PANGANDARAN. Dragon fruit is one type of potential fruits to be developed in the lowlands such as Pangandaran. Knowledge of dragon fruit cultivation in this area. An effort for the process of empowerment and community development for dragon fruit cultivation is with the socialization activities about the technology of dragon fruit cultivation. The purpose of this activity is to introduce dragon fruit plants to be cultivated in coastal areas of Pangandaran as one of the sources of food that rich with nutrition and support the improvement the nutrition of the community and allows to be an additional income for community. This activity was conducted in Cintaratu Village, Parigi, Pangandaran City by seminar and making the demonstration plot. The seminar was introduction of dragon fruit, explanation about the superiority and importance of dragon fruit as a source of nutrition, and also technology of dragon fruit cultivation in coastal area. In addition to making the demonstration plot (demplot) of dragon fruit on farmers' land. The results of this activities showed that there looks enthusiastic society to know more about what is the dragon fruit and how the dragon fruit culture techniques, so the dragon fruit in the area can develop.
\end{abstract}

KEYWORDS: Community, Cultivation, Dragon Fruit, Pangandaran.

* Corresponding Author: Departemen Budidaya Pertanian Fakultas Pertanian Universitas Padjadjaran; Jl. Raya Bandung Sumedang KM. 21, Hegarmanah, Jatinangor, Kabupaten Sumedang, Jawa Barat 45363, Indonesia; Email: syariful.mubarok@unpad.ac.id

Article History: Received: 05-11-2017; Revised: 01-12-2017; Accepted: 08-12-2017

Permalink: http://ppm.ejournal.id/index.php/pengabdian/article/view/27

How to cite (APA): Sudarjat, Isnaniawardhani, V., Qanit, M. A. H., \& Mubarok, S. (2017). Sosialisasi budidaya buah naga untuk daerah pesisir di desa Cintaratu, Parigi, kabupaten Pangandaran. Jurnal Pengabdian Pada Masyarakat, 2(2), 141-148.

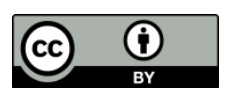

This is an open access article distributed under the terms of the Creative Commons Attribution 4.0 International License, which permits unrestricted use, distribution, and reproduction in any medium, provided the original work is properly cited. (C 2017, Sudarjat, Vijaya Isnaniawardhani, Muhamad Abdilah Hasan Qanit, Syariful Mubarok.

\section{PENDAHULUAN}

Pangandaran merupakan daerah dataran rendah yang berada di selatan Provinsi Jawa Barat. Luas wilayah Kabupaten Pangandaran yaitu $168.509 \mathrm{Ha}$ dengan luas laut 67.340 Ha dan luas lahan pertanian sekitar 13.495 Ha (Kasih, 2016). Umumnya tanaman yang banyak dikembangkan di Pangandaran adalah 
padi dan palawija. Akan tetapi komoditas tersebut belum mampu memberikan nilai ekonomis tinggi bagi warga sekitar. Pertimbangan Pangandaran sebagai kabupaten yang berkembang pada sektor pariwisata, khususnya pariwisata pantai, dan untuk mensinergikan program pertanian dan pariwisata, maka pengembangan buah naga di pangandaran dilakukan untuk mendukung program Agrowisata Pangandaran.

Buah naga (Hylocereus sp.) merupakan salah satu jenis buah-buahan yang termasuk komoditas hortikultura. Buah ini merupakan buah tropis yang habitatnya berasal dari Meksiko, Amerika Tengah dan sekarang sudah banyak dikembangkan di Indonesia. Salah satu jenis buah naga yang lebih dahulu dikenal di Indonesia adalah Hylocereus undatus (Kristanto, 2010). Buah naga mempunyai potensi untuk dikembangkan karena buah ini memiliki banyak keuntungan, baik dilihat dari segi ekonomi yang bernilai tinggi maupun dari segi manfaat untuk kesehatan. Buah naga mengandung banyak kandungan antioksidan maupun vitamin yang sangat penting untuk kesehatan. Buah naga bermanfaat untuk membantu menurunkan kadar glukosa darah, melancarkan pencernaan, penyeimbang kadar gula darah, pelindung kesehatan mulut, pencegah kanker usus, mengurangi kolesterol, pencegah pendarahan, dan mengobati keluhan keputihan (Nugroho, 2011). Memperhatikan berbagai manfaat tersebut, maka peluang pengembangan buah naga akan memberikan prospek yang baik.

Permintaan buah naga meningkat setiap tahunnya, baik di pasar domestik maupun pasar internasional. Pada saat ini, harga buah naga cukup tinggi, berkisar antara Rp 10.000 s.d. Rp. 23.000 di tingkat produsen dan Rp 25.000 s.d. Rp 30.000 di tingkat konsumen, sehingga sangat besar pengaruhnya terhadap perluasan komoditas buah naga di Indonesia. Buah naga di pasar ekspor jumlahnya masih sedikit, karena buah ini belum banyak dikenal di banyak negara, sehingga pengembangan agribisnis mempunyai prospek untuk peluang ekspor serta masih terbuka lebar untuk pasar di dalam negeri (Chusna, 2011; Kristriandiny \& Susanto, 2017). Melihat permintaan terhadap buah naga yang terus meningkat, maka perlu adanya peningkatan produksi buah naga di Indonesia, salah satunya adalah dengan pengembangan dan pencarian lokasi penanaman yang cocok untuk pertumbuhan buah naga di Indonesia.

Pengembangan agrowisata dengan buah naga di Pangandaran, harus dilakukan beberapa penelitian awal untuk mencari varietas buah naga yang cocok untuk dikembangkan di Pangandaran. Uji ini dimaksudkan untuk mendapatkan jenis atau varietas buah naga yang dapat menghasilkan buah yang berkuantitas dan berkualitas tinggi. Dewasa ini, pengembangan tanaman sudah mulai diarahkan pada tanaman yang spesifik lokasi (Syukur et al, 2010, p. 44). Oleh sebab itu, maka 
perlu dilakukan berbagai teknik budidaya dan pemilihan bibit atau jenis tanaman yang cocok ditanam di Pangandaran. Pemilihan jenis tanaman atau vairietas merupakan salah satu faktor yang sangat penting karena penampilan dan hasil dari suatu tanaman akan dipengaruhi oleh faktor genetik dan lingkungan. Varietas unggul yang ideal adalah berdaya hasil tinggi, tahan hama penyakit utama, dan stabil di berbagai target lingkungan. Maka, pemilihan varietas yang ideal dilakukan berdasarkan uji adaptasi jenis buah naga yang cocok untuk dikembangkan di Pangandaran. Uji adaptasi dilakukan untuk mengetahui keunggulan calon varietas tanaman terhadap lingkungan produksinya.

\section{METODE PELAKSANAAN}

Metode yang digunakan adalah metode partisipatif aktif dari peserta dalam mengikuti penyuluhan dan pembuatan demplot penanaman buah naga. Tahapan yang dilakukan dalam sosialisasi ini adalah: 1) Penyebaran/pengisian kuisioner sebelum dilakukan kegiatan; 2) Seminar dan penyuluhan tentang pengenalan buah naga, manfaat buah naga, teknik budidaya buah naga dan teknik pasca penan buah naga; 3) Penyebaran/pengisian kuisioner oleh peserta setelah dilakukannya kegiatan; 4) Pembuatan demplot penanaman buah naga.

\section{HASIL DAN PEMBAHASAN}

Tahap awal dari kegiatan sosialisasi ini adalah mengadakan pre-test, yakni penyebaran/pengisian kuisioner sebelum dilakukan kegiatan. Pre-test terdiri dari enam soal: (A) Pengetahuan peserta tentang tanaman buah naga (B) Pengalaman peserta dalam mengonsumsi buah naga (C) Pengetahuan peserta dalam kemungkinan budidaya buah naga di Desa Cintaratu (D) Ketertarikan peserta dalam budidaya tanaman buah naga (E) Ketertarikan peserta dalam budidaya jika disediakan benih/bibit tanaman buah naga (F) Keaktifan peserta untuk mengajak teman atau tetangga untuk ikut menanam tanaman buah naga tersebut di lahan masing-masing $(\mathrm{n}=30)$.

Berdasarkan data hasil pre-test (Gambar 1) dengan responden sebanyak 30 peserta penyuluhan dapat terlihat bahwa hampir seluruh peserta telah mengetahui tentang apa itu tanaman buah naga dan hanya sekitar 13 persen peserta saja yang belum mengetahui buah naga. Dari hasil ini dapat terlihat warga masyarakat di Pangandaran telah banyak mengetahui tentang tanaman buah naga. Hal ini dapat dipahami karena perkembangan buah naga sedang pesat, baik dalam budidaya maupun pemasaran yang tersebar di pelosok tanah air. Pengetahuan sebagian 
peserta mengenai buah naga tinggi, sebagian besar tidak hanya sebatas mengetahui nama dan bentuk, tetapi juga mengetahui rasa dari buah naga tersebut. Hasil kuisioner terlihat hanya sekitar 7 persen peserta yang belum pernah mencoba mengkonsumsi buah naga.

Hampir seluruh peserta penyuluhan sudah tahu bahwa buah naga dapat ditanam di Desa Cintaratu. Hal ini didasarkan karena mereka melihat tanaman buah naga seperti tanaman kaktus yang membutuhkan suhu tinggi untuk areal penanamannya ditambah terdapat peserta yang sudah mencoba dan mempunyai buah naga yang ditanam di areal pemukimannya, dan tanaman tersebut dapat menghasilkan buah. Karena kelebihan yang dimiliki buah naga dan kecocokan lokasi untuk sentra penanaman buah naga, para peserta sangat tertarik untuk dapat menanamnya.

Seluruh peserta penyuluhan memperlihatkan ketertarikan untuk membudidayakan tanaman buah naga, serta seluruh peserta mau mengajak petani atau warga lain yang tidak mengikuti penyuluhan untuk dapat mengembangkan dan membudidayakan buah naga di desanya. Secara umum berdasarkan data hasil kuisioner sebelum pelaksanaan penyuluhan (pre-test), maka dapat disimpulkan bahwa kegiatan penyuluhan tepat dilakukan di Desa Cintaratu melihat tingkat antusiasme tinggi masyarakat untuk budidaya dan mengembangan buah naga.
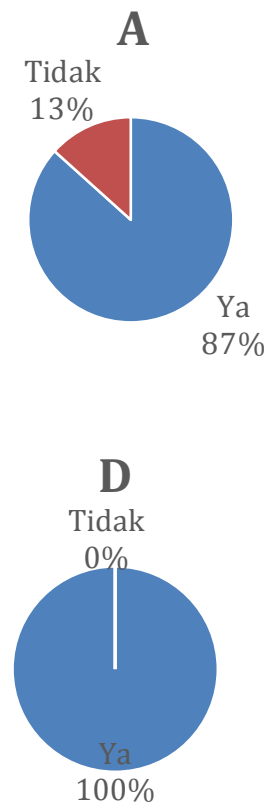
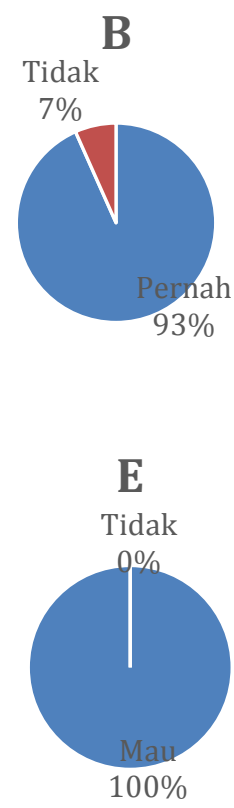
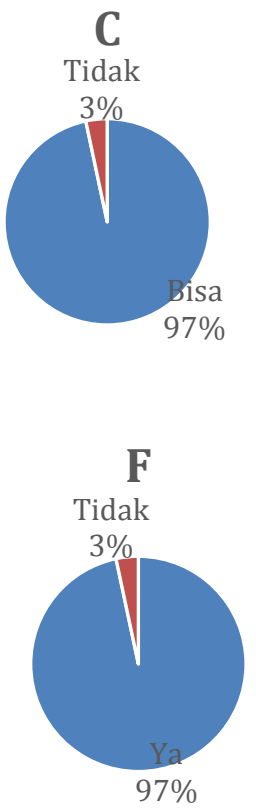

Gambar 1. Diagram Hasil Pre-test Kegiatan Sosialisasi dan Penyuluhan Budidaya Buah Naga 
Tahap selanjutnya adalah kegiatan penyuluhan. Penyuluhan diberikan untuk meningkatkan wawasan peserta mengenai fungsi dan manfaat buah naga untuk kesehatan, serta untuk peningkatan taraf hidup secara ekonomi. Peningkatan taraf hidup salah satunya dengan memanfaatkan dan membudidayakan buah naga dengan baik sesuai SOP budidaya buah naga yang benar, sehingga akan dihasilkan kualitas hasil panen yang optimal. Peningkatan wawasan tentang teknologi budidaya yang baik ini dilakukan dengan menyampaikan materi di depan para peserta penyuluhan yang nantinya diharapkan peserta dapat menyebarkan informasi ke seluruh warga lain di desanya, sehingga informasi yang diperoleh dapat disebarkan dengan baik kepada warga yang tidak mendapat penyuluhan.

Pada akhir acara penyuluhan dilakukan evaluasi (post-test) untuk melihat bagaimana respon peserta penyuluhan dan antusias mereka terhadap kegiatan penyuluhan yang sudah dilakukan (Gambar 2). Kuisioner post-test terdiri dari enam soal: (A) Ketertarikan peserta dalam mengetahui tanaman buah naga lebih banyak lagi setelah mengikuti penyuluhan (B) Ketertarikan peserta dalam melakukan budidaya tanaman buah naga di pekarangan rumah (C) Ketertarikan peserta dalam budidaya tanaman buah naga lebih luas lagi untuk tujuan pemasaran (D) Pendapat peserta mengenai keuntungan dalam budidaya tanaman buah naga (E) Ketersediaan peserta dalam membeli atau mencari benih tanaman buah naga jika tidak tersedia di desa (F) Ketersediaan peserta untuk bekerjasama untuk menanam tanaman buah naga yang dapat menghasilkan secara berkelanjutan $(\mathrm{n}=$ 30).

Dari 30 peserta penyuluhan, hampir semua peserta (97\%) tertarik ingin mengetahui lebih banyak lagi tentang buah naga, dan menunjukkan ketertarikannya untuk menanam tanaman buah naga di pekarangan rumahnya. Hanya sekitar 3 persen atau 1 orang saja yang tidak menunjukan ketertarikan untuk mengetahui buah naga secara detail. Ketertarikan untuk menanam buah naga muncul setelah para peserta mengetahui bahwa budidaya buah naga itu pada dasarnya tidak rumit, jika mengetahui faktor tumbuh yang dapat berpengaruh terhadap pertumbuhan tanaman.

Dari 30 responden, sekitar 3 orang responden atau (10\%) dari total peserta tertarik untuk membudidayakan buah naga hanya untuk hobi saja, mereka tidak tertarik untuk membuat bisnis penanaman buah naga, namun sisa dari responden yaitu sekitar 27 orang sangat tertarik untuk menjadikan buah naga sebagai skala usaha bisnis yang akan meningkatkan taraf hidup mereka. Ketertarikan untuk menjadikan budidaya tanaman buah naga ini sebagai bisnis dikarenakan menurut 
mereka usaha buah naga itu menguntungkan. Hal ini didasarkan pada permintaan pasar akan buah naga yang masih terbuka dengan lebar, baik untuk pemasaran buahnya maupun bibitnya. Karena untuk jenis buah naga baru satu bibit harganya bias mencapai harga Rp. 60.000. Selain dijual dalam bentuk tanaman atau buah segarnya, mereka berpikir bahwa hasil buah naga dapat menjadi suatu hasil olahan yang bernilai tinggi yang salah satunya dibuat kue, selai, manisan kering buah naga atau jenis makanan lainnya (Herianto, Hamzah, \& Yusmarini, 2015; Wahyuni, 2011).
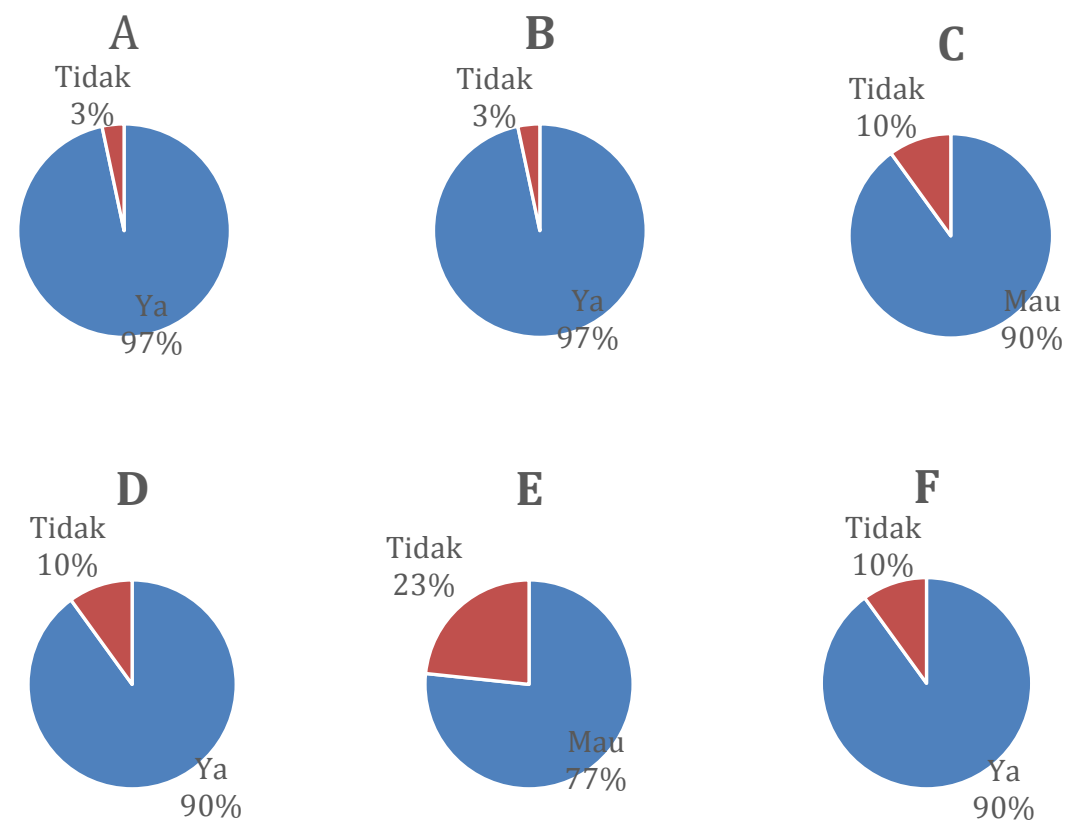

\section{Gambar2. Diagram Hasil Post-test Kegiatan Sosialisasi dan Penyuluhan Budidaya Buah Naga}

Keinginan masyarakat untuk mengembangkan dan membudidayakan buah naga terlihat hanya sebatas membudidayakannya saja. Keingintahuan mereka akan jenis-jenis buah naga baru masih terlihat kurang, hal ini terlihat dari sekitar 27 (90\%) orang yang tertarik untuk mengembangkan buah naga di daerahnya hanya sekitar 23 orang yang mau berusaha mencari sendiri dan membeli bibit sendiri jika bibit tersebut tidak tersedia di desa ini. Dari data ini menunjukkan bahwa inisiatif warga untuk mengembangkan desanya sendiri masih dirasakan kurang. Oleh sebab itu perlu adanya penekanan yang lebih tinggi untuk meningkatkan kesadaran warga akan pentingnya inisiatif dan kreatifitas untuk pengembangan wilayah mereka. Untuk meningkatkannya kreatifitas warga salah satunya adalah dengan 
melakukannya kerjasama dalam hal budidaya tanaman baik itu dalam hal penyediaan bibit atau sarana dan prasarana lainnya. Dari hasil kuisoner dari 30 responden menunjukkan bahwa sekitar 27 orang bersedia untuk menanam menanam tanaman.

\section{SIMPULAN}

Program sosialisasi budidaya buah naga di Desa Cintaratu telah berhasil menginformasikan pentingnya tanaman buah naga untuk dikembangkan di daerah ini yang dapat digunakan sebagai tanaman bergizi sekaligus memotivasi para petani khususnya tokoh-tokoh kelompok tani untuk mencoba menanam tanaman buah naga. Antusias warga sangat tinggi untuk pengembangan buah naga di desa ini karena potensi dan kondisi lingkungan yang sesuai dengan syarat tumbuh buah naga. Selain itu sektor pariwisata di desa ini dapat mendukung terciptanya sektor pariwisata baru ke arah agrowisata buah naga.

Untuk mengoptimalisasi capaian terciptanya sektor pariwisata baru ke arah agrowisata buah naga, maka perlu dilakukan pengujian lebih lanjut untuk penentuan jenis buah naga apa yang cocok ditanam di Desa Cintaratu Kecamatan Parigi, Pangandaran. Selain itu, perlu dilakukan pendampingan tentang tata cara budidaya yang benar dan sesuai dengan SOP budidaya buah naga.

\section{REFERENSI}

Chusna, C. B. (2011). Peluang bisnis buah naga di Indonesia. Yogyakarta: Universitas AMIKOM Yogyakarta.

Herianto, A., \& Hamzah, F., \& Yusmarini. (2015). Studi pemanfaatan buah pisang mas (Musa Acuminata) dan buah naga merah (Hylocereus Polyrhizus) dalam pembuatan selai. Jurnal Online Mahasiswa (JOM) FAPERTA, 2(2), 1-12.

Kasih, E. A. (2016). Profil kabupaten Pangandaran, Daerah otonomi baru yang penuh potensi. Retrieved August 29, 2017, from Eri Anggoro Kasih website: http://www.erianggorokasih.com/2016/12/profil-kabupaten-pangandarandaerah.html.

KKNM Unpad. (2017). Desa Cintaratu. Retrieved August 29, 2017, from Berita KKNM Unpad website: http://kknm.unpad.ac.id/cintaratu/

Kristanto, D. (2010). Buah naga, Pembudidayaan di pot dan di kebun. Cetakan IV (Edisi revisi). Jakarta: Penebar Swadaya. 
Sosialisasi Budidaya Buah Naga Untuk Daerah Pesisir di Desa Cintaratu,

Parigi, Kabupaten Pangandaran

Kristriandiny, O., \& Susanto, S. (2017). Budi daya buah naga putih (Hylocereus undatus) di Sleman, Yogyakarta: Panen dan pascapanen. Buletin Agrohorti, 4(1), 1-8.

Syukur, M., Sujiprihati, S., Yunianti, R., \& Kusumah, D. A. (2010). Evaluasi daya hasil cabai hibrida dan daya adaptasinya di empat lokasi dalam dua tahun. Jurnal Agronomi Indonesia (Indonesian Journal of Agronomy), 38(1), 43-51.

Wahyuni, R. (2011). Optimasi pengolahan kembang gula jelly campuran kulit dan daging buah naga super merah (Hylocereus costaricensis) dan prakiraan biaya produksi. Teknologi Pangan, 1(1), 1-8. 